\title{
PENGARUH PENGAKTIFAN KEMBALI LEM SINTETIS TERHADAP KEKUATAN REKAT (PEEL STRENGTH) PADA PROSES PENGESOLAN SEPATU PLASTIK, SOL KARET, SISTEM PRES DINGIN
}

\author{
oleh : Penny Setyowati, Sri Nadilah dan Murwati
}

\section{ABSTRACT}

This research is an experiment on the influence of reactivated temperature and time of synthetic adhesive upon peel strength on plastic shoes adhesion processes, made at synthetic leather uppers, rubber soles and used GB and PC adhesives. The upper side of shoes and sole are brushed with $\mathrm{PC}$ adhesive as a supporting adhesive and then continued with GB adhesive, to be aged for at least 24 hours until they become dried. Then they are reactivated at the temperature varied between $60^{\circ} \mathrm{C}-90^{\circ} \mathrm{C}$ with temperature interval of $10^{\circ} \mathrm{C}$, and time varied between $10-25$ minutes with time interval of 5 minutes. They are stuck and pressed at $2.5 \mathrm{~kg} / \mathrm{cm} 2$ for 2 minutes. The peel test results is calculated by statistical method. So that the experiment result proved that the influence of heat on synthetic adhesive reactivated is to increase adhesion. Optimal peel test value was reached at the reactivated temperature of $80^{\circ} \mathrm{C}$ and time of 15 minutes.

\section{INTISARI}

Penelitian ini merupakan penelitian mengenai pengaruh suhu dan waktu pengaktifan kembali lem sintetis terhadap kekuatan rekat (peel strength) pada proses pengesolan/pengeleman sepatu plastik, atasan kulit imitasi, sol karet, lem yang digunakan lem sintetis GB dan PC. Sepatu bagian atas dan sol diolesi lem PC (sebagai lem pembantu) kemudian GB, dibiarkan minimal 24 jam sampai lem menjadi kering, kemudian diaktifkan pada suhu bervariasi $60^{\circ} \mathrm{C}-90^{\circ} \mathrm{C}$ dengan interval $10^{\circ} \mathrm{C}$ dan waktu $10-25$ menit dengan interval 5 menit. Dilekatkan satu sama lain, dipres selama 2 menit tekanan $2,5 \mathrm{~kg} / \mathrm{cm} 2$. Uji kuat rekat antara sol luar dengan sol dalam (peel test) dilakukan dengan alat tensile strength. Hasilnya dievaluasi secara statistik dan disimpulkan bahwa : Pengaruh pemanasan pada pengaktifan kembali lem sintetis adalah meningkatkan nilai kuat rekatnya. Suhu dan waktu pengaktifan yang memberikan nilai kuat rekat tertinggi adalah suhu $80^{\circ} \mathrm{C}$ waktu 15 menit. 


\section{PENDAHULUAN}

Pada pengerjaan pembuatan sepatu, penempelan bagian atasan dengan sol luar secara sistim lem merupakan rangkaian pengerjaan terpenting yang sangat menentukan kekuatan pada sepatu yang dibuat.

Bagi pembuat sepatu (pengrajin sepatu) dengan produksi yang tidak begitu besar, proses pengeleman yaitu mulai dari pengolesan lem sampai dengan perekatan bagian atasan dengan sol luar dapat dilakukan dalam selang waktu yang tidak terlalu lama. Tetapi bagi para pengrajin dengan produksi yang lebih besar, biasanya pengolesan lem dilakukan secara masal yang melibatkan berpuluh-puluh /beratus-ratus pasang sepatu. Sehingga pada saat perekatan, lem sudah terlalu kering dan sulit untuk direkatkan satu sama lain. Untuk itu lem yang sudah kering tersebut harus diaktifkan kembali dengan cara dipanaskan dulu. Adapun maksud pemanasan adalah untuk melelehkan/melunakan lem yang sudah kering, sehingga proses perekatan dapat berlangsung lebih mudah. Mengingat hal tersebut diatas, maka perlu dilakukan suatu pengamatan sampai sejauh mana pengaruh pengaktifan lem tersebut terhadap kekuatan rekatnya sehingga diperoleh suatu sistim pengeleman sepatu yang tepat dan mantap.

\section{TINJAUAN PUSTAKA}

Beberapa faktor yang mendukung suatu perekatan/pengeleman adalah : (pustaka 1).

\section{Sifat kekasaran dari "solid surface"}

Tujuan pengasaran "solid surface" adalah untuk memperluas permukaan sehingga pembasahan/kontak antara bahan perekat (lem) dengan

"solid surface" menjadi lebih sempurna.

\section{Kekuatan mekanik}

Kekuatan mekanik (pukulan) yang diterapkan pada proses pengeleman akan menambah daya tahan/kekuatan dari pada pengeleman tersebut.

\section{Pemanasan dan penekanan}

Dalam proses pengeleman, faktor panas dan tekanan dapat menambah kemampuan dari lem untuk mengabsorbsi, membasahi (wetting) dan menyebar kedalam permukaan benda yang akan dilem (adherend). Disamping itu, faktor panas juga dapat membantu meningkatkan kekuatan reaksi kimia antara lem dengan benda yang akan direkatkan (adherend). Panas dapat diberikan juga kepada adhesive (lem) yang sudah mengering (kehilangan solventnya). Karena lelehan adhesive panas akan memperkuat daya rekat lem dengan "adherend", apalagi bila ditambah dengan penekanan yang memadai.

Dengan dasar itulah, maka peristiwa pengaktifan kembali lem yang sudah kering pada pembuatan sepatu akan dapat menambah daya rekat lem.

Menurut "IRVING SKEITS" daya tahan lem sintetis terhadap panas sangat bervariasi sekali tergantung dari formulanya. "Service temperature" lem karet sintetis (SBR) berkisar antara $160^{\circ} \mathrm{F}$ (pustaka 2).

\section{Surface treatment (perlakuan permukaan)}

"Surface treatment" dari pada "adherend" adalah sesuai dengan teori "Surface energetics" bahwa permukaan yang dikenai perlakuan dengan menggunakan bahan kimia akan menghasilkan sesuatu permukaan yang mempunyai "Critical surface tension" yang lebih besar.

Dengan demikian maka, dalam peristiwa pengeleman akan terjadi kontak yang sempurna antara adhesive dengan "Solid surface" (yang sudah diberi perlakuan), sehingga menghasilkan daya rekat yang lebih kuat.

\section{MATERI DAN METODE}

\section{Materi}

\subsection{Bahan}

- bahan-bahan untuk atasan sepatu (kulit imitasi, kain lapis elastik dan lain-lain).

- bahan-bahan untuk bawahan sepatu (sol karet, insol karton kulit, pengeras dan lain-lain).

- bahan-bahan pembantu (lem latex, herin, cat sol).

- lem sintetik GB dan PC.

\subsection{Alat}

- alat untuk pembuatan sepatu (mesin jahit, acuan dan alat-alat pembantu lain).

- alat pemanas untuk mengaktifkan lem

- mesin pres sepatu

- alat uji peel strength (tensile strength machine).

\section{Metode}

\subsection{Persiapan bahan}

pembuatan kudungan (bagian atas) sepatu pengopenan sepatu 


\subsection{Proses pengeleman (pengesolan)}

- Bagian-bagian yang akan dilem (sepatu bagian atas dan sol luar) dikasarkan dulu dan dibersihkan dari kotoran-kotoran yang melekat.

Lem PC (sebagai lem pembantu) dioleskan dulu sampai merata pada kedua bagian yang akan direkatkan, setelah kering baru ditumpangi dengan olesan lem GB (sebagai lem utama). Kemudian dibiarkan minimal selama 24 jam sampai lem kering.

- Sebelum ditempelkan kedua bagian sepatu tersebut dimasukkan kedalam alat pemanas yang berfungsi sebagai alat pengaktif lem. Pengaktifan lem dilakukan dengan suhu dan waktu yang bervariasi. Suhu $60 \mathrm{C}-90 \mathrm{C}$ interval $10 \mathrm{C}$, waktu $10^{\prime}-25^{\prime}$ interval 5' (ada 16 kombinasi suhu $\mathrm{X}$ waktu).

- Setelah lem diaktifkan kembali, barulah kedua bagian direkatkan satu sama lain secara langsung (tidak boleh diulang), dipres dengan beban $2 \frac{1}{2} \mathrm{~kg}$ selama 2 menit.

- Sepatu baru boleh dilepas dari acuan, bila proses pengeleman sudah sempurna (didiamkan minimal 24 jam).

\subsection{Pengujian sepatu}

Pengujian yang dilakukan adalah uji kuat rekat sol luar dengan sol dalam (peel test) menggunakan "Tensile Strength Machine".

\subsection{Evaluasi hasil}

- untuk penentuan kondisi yang optimal (suhu dan waktu) pengaktifan kembali lem, hasil-hasil uji kuat rekat dievaluasi dengan metode faktorial.

- untuk mengetahui pengaruh pengaktifan lem, maka harus dibandingkan antara nilai kuat rekat pada proses pengeleman tanpa pengaktifan dengan nilai kuat rekat yang disertai pengaktifan lem.

\section{HASIL PENELITIAN DAN PEMBAHASAN}

1. Hasil uji kuat rekat sol luar dengan sol dalam (Peel test) $(\mathrm{gr} / \mathrm{cm})$-sepatu plastik sol karet, sistem pres dingin dengan pengaktifan kembali lem, dapat dilihat pada tabel 1. berikut :
Tabel 1. Hasil uji kuat rekat sol luar dengan sol dalam (Peel test) $\mathrm{gr} / \mathrm{cm}$, sepatu plastik, sol karet, sistem pres dingin dengan pengaktifan kembali lem sintetis *)

\begin{tabular}{c|c|r|r|r|r|r}
\hline \multirow{2}{*}{$\begin{array}{c}\text { Suhu } \\
\text { Pengaktifan }\end{array}$} & \multirow{2}{*}{$\begin{array}{c}\text { Waktu } \\
\text { Pengaktifan } \\
\text { C }\end{array}$} & \multicolumn{3}{|c|}{ Ulangan } & \multirow{2}{*}{ Total } & \multirow{2}{*}{ Rata-rata } \\
\cline { 3 - 6 } (menit) & 1 & 2 & 3 & & \\
\hline \multirow{2}{*}{60} & 10 & 1354,2 & 1579,0 & 2449,0 & 5382,2 & 1342,7 \\
& 15 & 2000,0 & 3111,0 & 3222,0 & 8333,0 & 2777,7 \\
& 20 & 3286,0 & 3900,0 & 4636,0 & 11822,0 & 3940,7 \\
& 25 & 3519,0 & 2727,0 & 3091,0 & 9337,0 & 3112,3 \\
\hline \multirow{2}{*}{70} & 10 & 1509,0 & 1667,0 & 1852,0 & 5028,0 & 1676,0 \\
& 15 & 2456,0 & 2581,0 & 2500,0 & 7537,0 & 2512,3 \\
& 20 & 2586,0 & 2364,0 & 2546,0 & 7496,0 & 2498,7 \\
& 25 & 2368,0 & 2812,0 & 2896,0 & 8070,0 & 2690,0 \\
\hline \multirow{2}{*}{80} & 10 & 4571,0 & 4756,0 & 4625,0 & 13952,0 & 4650,7 \\
& 15 & 4615,0 & 3778,0 & 5750,0 & 14143,0 & 4714,3 \\
& 20 & 3000,0 & 3555,0 & 2647,0 & 9202,0 & 3067,3 \\
& 25 & 3000,0 & 3304,0 & 3132,0 & 9436,0 & 3142,3 \\
\hline \multirow{2}{*}{90} & 10 & 1886,0 & 2238,0 & 2414,0 & 6538,0 & 2179,3 \\
& 15 & 4090,0 & 3728,0 & 4082,0 & 11900,0 & 3966,7 \\
& 20 & 2900,0 & 2889,0 & 3461,0 & 9250,0 & 3083,3 \\
& 25 & 3135,0 & 3396,0 & 3091,0 & 9622,0 & 3207,3 \\
\hline
\end{tabular}

*) Sumber : Pustaka 4.

Perhitungan statistik factorial untuk menentukan kondisi pengaktifan yang menghasilkan nilai uji kuat rekat (Peel test) yang tertinggi.

\section{ANOVA untuk uji kuat rekat sol luar dengan sol dalam (Peel test)}

\begin{tabular}{l|r|r|c|c|c}
\hline \multicolumn{1}{c|}{ Sumber Variasi } & df & \multicolumn{1}{c|}{ SS } & MS & F hitung & F tabel 5\% \\
\hline - Ulangan & 2 & 1205033,2 & 602516,6 & & \\
- Perlakuan & 15 & 36066149,3 & 2404409,95 & & \\
- Suhu pengaktifan & 3 & 14814924,6 & 4938308,2 & 30,87 & 2,92 \\
- Waktu pengaktifan & 3 & 5166481,2 & 1722160,2 & 10,76 & 2,92 \\
- Interaksi suhu X & 9 & 16084743,5 & 1787193,7 & 11,17 & 2,21 \\
waktu pengaktifan & & & & & \\
- Error (kekeliruan) & 30 & 4799751,7 & 159991,72 & & \\
\hline \multicolumn{1}{c}{ Total } & 47 & & & & \\
\hline
\end{tabular}

Vol. VI. No. 10-11 1990/1991 
$\mathrm{F}$ hitung $>\mathrm{F}$ tabel $5 \% \rightarrow$ diantara 16 kombinasi periakuan ada perbedaan nyata.

1.1. Perhitungan LSD $5 \%$ ditinjau dari faktor suhu pengaktifan

LSD $5 \%=320,0584$

Dari notasi dengan LSD $5 \% \rightarrow$ nilai uji kuat rekat tertinggi dicapai pada suhu $80 \mathrm{C}$.

1.2. Perhitungan LSD $5 \%$ ditinjau dari waktu pengaktifan

LSD $5 \%=320,0584$

Dari notasi dengan LSD $5 \% \rightarrow$ nilai uji kuat rekat tertinggi dicapai pada waktu pengaktifan 15 menit.

1.3. Perhitungan MDRS ditinjau dari interaksi suhu pengaktifan dan waktu pengaktifan

Menentukan SED : $\mathrm{Sx}=230,9341$, derajad kebebasan $=$ df error $=30 \longrightarrow$ MDRS untuk masing-masing golongan dapat dihitung dengan pertolongan tabel

Dari notasi MDRS $\rightarrow$ nilai uji kuat rekat tertinggi dicapai pada kombinasi/interaksi suhu pengaktifan dan waktu pengaktifan $80 \mathrm{C}$ selama 15 menit.

Dari perhitungan statistik diatas, baik ditinjau dari faktor suhu pengaktifan, faktor waktu pengaktifan maupun faktor interaksinya, nilai uji kuat rekat sol luar dengan sol dalam (peel test) yang tertinggi dicapai pada suhu pengaktifan $80^{\circ} \mathrm{C}$ dengan waktu 15 menit yaitu sebesar $=4714,3$ $\mathrm{gr} / \mathrm{cm}$.

Perbandingan nilai uji kuat rekat sol luar dengan sol dalam pada proses pengesolan/pengeleman tanpa pengaktifan lem (dari pustaka 3) dengan yang diaktifkan dapat dilihat pada tabel 2 .
Tabel 2. Hasil uji kuat rekat (peel test) $(\mathrm{gr} / \mathrm{cm})$ pengeleman/pengesolan sepatu plastik sol karet, sistem pres dingin tanpa proses pengaktifan kembali lem dan sistem pres dingin dengan pengangtifan kembali lem.

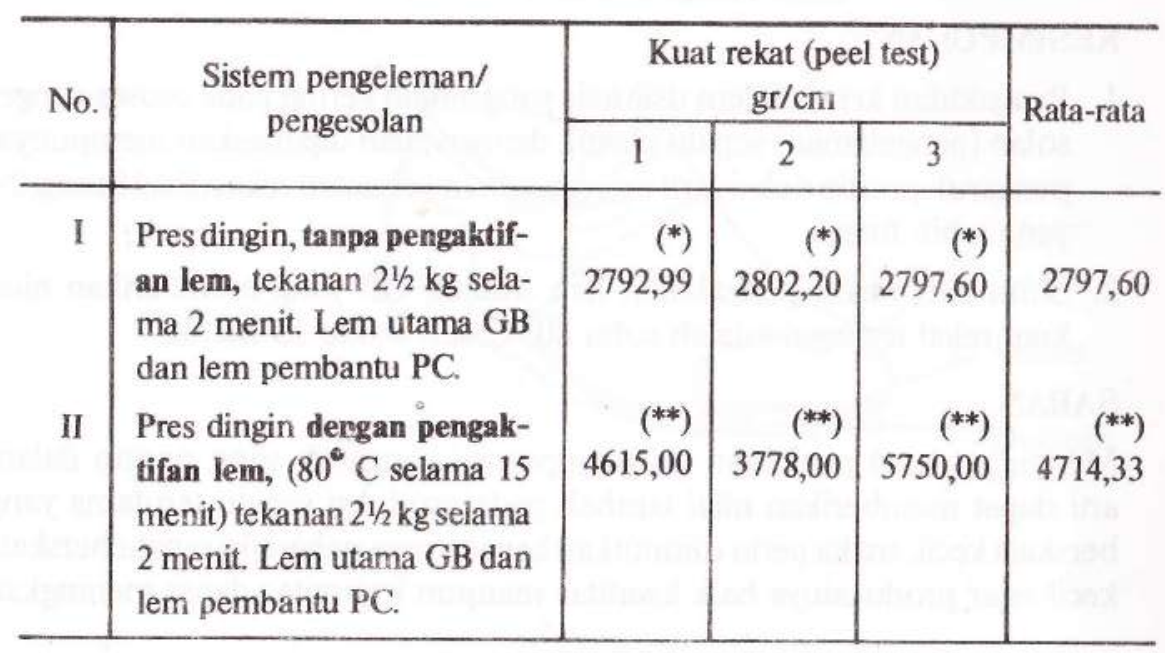

$\left(^{*}\right)$ Diambil dari pustaka 3

(**) Diambil dari pustaka 4

Untuk membandingkan kedua sistem pengeleman tersebut, dilakukan analisa Uji "t" "menurut student" dengan taraf kepercayaan $95 \%$.

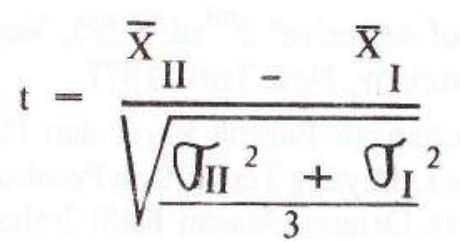

$$
\begin{aligned}
& \sigma_{I}{ }^{2}=\frac{\sum\left(x_{n}-\bar{x}_{I}\right)^{2}}{3}=14,14 \\
& \sigma_{I I}{ }^{2}=\frac{\sum\left(x_{n}-\bar{x}_{I I}\right)^{2}}{3}=653064,16 \\
& { }_{\text {hitung }}=4,11
\end{aligned}
$$

untuk DB $=4 \rightarrow$ dari tabel diperoleh $-\mathrm{t}_{0,975} \mathrm{~s} / \mathrm{d}+\mathrm{t}_{0,975}$ adalah $-2,776 \mathrm{~s} / \mathrm{d}+2,776 \rightarrow t_{\text {hitung }}>t_{\text {tabel }} \rightarrow$ berarti ada perbedaan yang nyata antara kedua sistem pengeleman tersebut.

Vol. VI. No. 10-11 1990/1991 
Nilai uji kuat rekat (Peel test) yang terbaik/tertinggi adalah pada sistem ke II yaitu sistem pres dingin dengan pengaktifan lem.

Jadi pengaktifan kembali lem sintetis pada proses pengesolan/pengeleman dapat menghasilkan kuat rekat yang jauh lebih baik dibandingkan dengan sistem pengeleman biasa (tanpa pengaktifan lem).

\section{KESIMPULAN}

1. Pengaktifan kembali lem dsintetis yang sudah kering pada proses pengesolan (pengeleman) sepatu plastik dengan jalan dipanaskan mempunyai pengaruh positip dalam arti menghasilkan kekuatan rekat (Peel Strength) yang lebih tinggi.

2. Suhu dan waktu pengaktifan lem sintetik GB yang memberikan nilai kuat rekat tertinggi adalah suhu $80^{\circ} \mathrm{C}$ dan waktu 15 menit.

\section{SARAN}

Mengingat hasil penelitian ini mempunyai pengaruh yang positip dalam arti dapat memberikan nilai tambah pada produksi sepatu terutama yang berskala kecil, maka perlu diinputkan kepada para pengrajin sepatu berskala kecil agar produksinya baik kwalitas maupun kwantitas dapat meningkat.

\section{DAFTAR PUSTAKA}

1. Charles V.Cagle, "Hand Book of Adhesive Banding" p2-1 s/d 2-8, MC-Graw-Hill Book Company, New York 1982.

2. Irving Skeitst, "Hand Book of Adhesive" $2^{\text {nd }}$ ed, p 295, Van Nostrand Reinhold Company, New York, 1977.

3. Seksi Percobaan, Balai Pengembangan Barang Karet dan Plastik, "Penentuan Jenis Lem yang Tepat Pada Pembuatan Sepatu Umum Pria Dengan Atasan Kulit Imitasi dan Sol Karet”, Departemen Perindustrian, 1986.

4. Seksi Percobaan, Balai Pengembangan Barang Karet dan Plastik, "Percobaan Pembuatan Sepatu Plastik, Sol Karet secara Pengeleman, Sistem Press Dingin Melalui Pengaktifan Kembali Lem Sintetis", Departemen Perindustrian, 1988. 
(A) getorg of

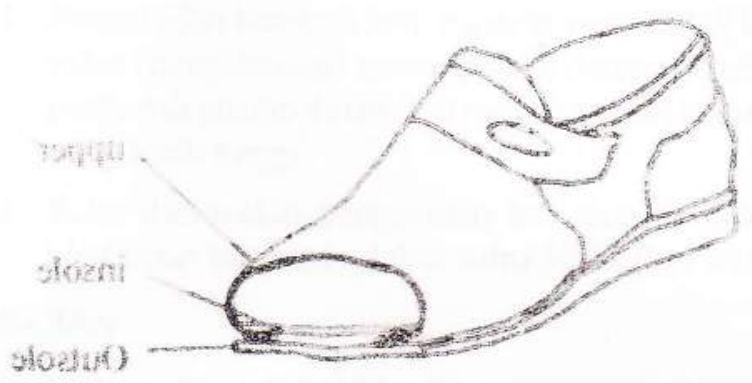

semoeer II-01 on fy dov 